\title{
Children, biobanks and the scope of parental consent
}

\author{
Kristien Hens $^{\star, 1}$, Jean-Jacques Cassiman ${ }^{2}$, Herman Nys $^{1}$ and Kris Dierickx ${ }^{1}$
}

The use of stored tissue samples from children for genetic research raises specific ethical questions that are not all analogous to those raised when adult participants are concerned. These include issues with regard to consent, as it is typically a parent who consents to the use of samples from children. In this paper, we discuss the scope of parental consent. This scope has a temporal dimension and one related to the content of consent. It is not questioned that the temporal scope of parental consent is limited and that young adults have the right to decide on the fate of their samples when they reach the age of maturity. With regard to the content of consent, the question remains whether parents are allowed to give full broad consent to any possible future research on the samples of their children. We argue that they should not be allowed to do so, based on two premises. First, it is generally acknowledged that children have a right to express their own values and that they should be given the opportunity to develop their own autonomy as they grow older. Second, research and science are not completely value-free and some types of research may be more sensitive than other types. Children should be given the opportunity to express their values also in this respect.

European Journal of Human Genetics (2011) 19, 735-739; doi:10.1038/ejhg.2011.29; published online 9 March 2011

Keywords: research ethics; consent; minors; children; biobank

\section{INTRODUCTION}

The use of stored tissue samples from children for genetic research raises specific ethical questions that are not all analogous to those raised when adult participants are concerned. The most obvious difference is that for small children, at least, their DNA is used for research without their own consent. As it is typically a parent who consents to the use of the samples, it is unsure what the wishes of the child would be. The issue of consent can furthermore be split up into some issues, which, in themselves, have been more or less discussed in guidelines and ethics literature. These issues involve questions about who should consent, the right of a child to assent or dissent, the right of a child to withdraw their data and the scope of parental consent. The scope of parental consent has in its turn two dimensions. First, there is a temporal dimension: do parents have the right to consent to the storage and use of pediatric material ad aeternam or do children have to be asked to re-consent when they reach the age of competence. Second, there is a dimension of content. Do parents have the right to consent to any possible research on the stored tissue samples of their children, the so-called broad consent, or are they only allowed to give specific consent? Although a substantial theoretical and empirical corpus already exists on the topic of broad versus specific consent when adult participants are concerned, the question is as of yet relatively untouched when participants are children. In this paper, we shall first give an overview of the existing literature with regard to biobanks, children and consent. We shall then briefly describe the issue of broad versus specific consent as it is discussed in the context of adults, and provide a reflection on how this issue should be tackled when children are concerned.

\section{CHILDREN AND CONSENT: EXISTING LITERATURE}

A recent review has shown that guidelines on the use of stored tissue samples from minors discuss the following issues: the fact that a parent or legal guardian must consent, that a child's assent and dissent should be taken into account, and that children should be re-contacted as young adults either when they are old enough to understand the research or when they reach the age of competence. ${ }^{1}$ A review of the literature has identified similar themes. ${ }^{2}$ There is consensus that biological samples from children should not be used without consent or at least notification, and that the people best suited to give this consent are the parents or the legal guardian. In this respect, the Organizations of Medical Science (CIOMS) guideline mentions, for example, that 'the parent or guardian who gives permission for a child to participate in research should be given the opportunity, to a reasonable extent, to observe the research as it proceeds, so as to be able to withdraw the child if the parent or guardian decides it is in the child's best interest to do so. ${ }^{3}$ Holm ${ }^{4}$ justifies this right of the parents to consent by referring to the fact that biobank research in most cases does not have negative effects on children. Also other authors seem to suggest that consent by one parent is enough, although one may ask whether the fact that genetic research is involved might complicate this matter, as a child's genes are shared with both the parents. However, many children do not live with both biological parents, and a too stringent requirement in this respect may hamper research. Hence, we think the fact that both parents should consent to such research could be seen as a best practice rather than an absolute rule. ${ }^{5}$

Several guidelines and the ethics literature mention the fact that minors, as soon as they are mentally capable to do so, should be asked to assent to research, and that their dissent should be taken into account. ${ }^{1}$ For example, in papers from Holm and Helgesson, ${ }^{4,6}$ it is stressed that older children should be asked to assent and dissent. Helgesson links this to the fact that children develop autonomy by being given the chance to exercise it to the degree they are capable of. There is less certainty about whether there should be a fixed-age

${ }^{1}$ Centre for Biomedical Ethics and Law, Department of Public Health, Katholieke Universiteit Leuven, Leuven, Belgium; ${ }^{2}$ Department of Human Genetics, Katholieke Universiteit Leuven, Leuven, Belgium

*Correspondence: Dr K Hens, Centre for Biomedical Ethics and Law, Department of Public Health, Katholieke Universiteit Leuven, Kapucijnenvoer 35/3 Box 7001, Leuven 3000, Belgium. Tel:+32 16 332604; Fax:+32 163369 52; E-mail: Kristien.Hens@med.kuleuven.be

Received 16 July 2010; revised 11 January 2011; accepted 28 January 2011; published online 9 March 2011 
threshold for assent, or whether this should be evaluated on a case-bycase basis. A qualitative study based on interviews with professionals in the field of stored tissue samples from minors has suggested that professionals do not believe in fixed-age thresholds and that they see legal requirements to ask small children to sign papers as unrealistic and bureaucratic. ${ }^{7}$ Ashcroft et al ${ }^{8}$ have also suggested that maturity is a better criterion than age because the capacity to assent is dependent on social context and personal experience. We agree with this stance. We also believe that in many cohort studies with children or studies in the context of specific diseases, there is plenty of opportunity for informal assessments of maturity, as in such cases there is frequent contact between researchers and children. In any case, all children, also very small ones, have a right to information at a level they can understand. It is also the task of the professional, be it a researcher, a clinician or a research nurse, together with the parents, to assess the value of a child's dissent. On one hand, many children may have an unreasonable fear of certain procedures, a fear, which might be easily overcome by rewards, such as a sticker or small present, from the researcher or the parent. On the other hand, no child should be subjected to procedures she obviously dislikes, whatever the parents' or researcher's noble aims be to aid in the progress of science. And of course this assumes that an ethics committee, with a pediatrician as member, has already assessed the burden of the procedures and decided that it is reasonable.

An important question with regard to consent to research on samples that are stored over a longer period of time is related to the scope of consent. This scope has two dimensions: a temporal one and one related to content. The temporal dimension is discussed to some extent in existing literature. Guidelines and the literature agree that the temporal scope of parental consent is valid until the child reaches the age of competence. ${ }^{2,1}$ In this respect, CIOMS mentions that 'If such research subjects, including children, become capable of giving independent informed consent during the research, their consent to continued participation should be obtained'. ${ }^{3}$ Burke and Diekema, ${ }^{9}$ for example, are in favor of such re-consent because this would allow minors to participate more as they grow older, a thought, which is supported by empirical research. ${ }^{10}$ However, this may be impossible in some cases: Samples may be stored for many years, and there may be no possibility to re-contact the children. One qualitative focus group study has suggested that in this case, a best effort to re-contact young adults is sufficient, but that it is still seen as a sign of respect from researchers. ${ }^{11}$ Another study, however, found that children should be re-contacted. ${ }^{12}$ In any case, there was consensus that minors should be allowed to withdraw their samples and data from a study for which their parents consented. Holm ${ }^{4}$ states in this respect that as children have not been able to autonomously consent and give up the right to withdraw at the moment of donation, the right to withdraw for children is more important than the right to withdraw for adult donors.

We agree that in principle, biobankers should make an effort to re-contact young adults for reconsent once they are capable of giving consent. We also agree that young adults have the right to withdraw their samples and data. In this respect, the temporal scope of parental consent is limited.

A topic much less discussed in the context of pediatric biobanks is that of the content of parental consent. Are parents allowed to give 'broad consent' to any possible future genetic research on their children's samples or should this consent be better specified. In next paragraphs we shall describe the existing discussion of broad versus specific consent in general, and then specify why we think the issues are different when participants are minors.

\section{BROAD VERSUS SPECIFIC CONSENT}

Traditional informed consent, which assumes the fully informed, mostly written consent of a participant to a specific research proposal, has become the theoretical standard in research bioethics, as it is deemed the most appropriate sign of respect for the autonomy of an individual. However, it is not specifically well suited for the inclusion of samples in biobanks. Such biobanks form a resource for future research, the specific content and extent of which, at the time of storage, are often unknown. Therefore, it is argued that consent for such research is never truly informed. ${ }^{13}$ But re-contacting donors for consent to each and every different research protocol is costly and may hamper the advancement of research. ${ }^{14}$ Some have argued that these technical difficulties do not provide a sufficient ethical ground for broad consent. ${ }^{15}$ However, it has also been argued in the theoretical literature that principles of justice and solidarity can justify consent procedures, which diverge from the ideal standard of previous, free, informed and explicit consent. ${ }^{16}$ Such principles are based on the concept of medical science as a 'collective good', a notion, which may be true in the case of some research aims, but may that be naive in other cases. ${ }^{17}$ Also, there is a range of possibilities between giving true informed and specific consent, and completely blanket consent, which implies that no restrictions are put on the scope and direction of the possible research. ${ }^{18}$ Broad consent, as it is now often deployed, is still subject to certain restrictions, and not completely analogous with 'blanket consent'. A study by Elger et al ${ }^{19}$ regarding the European guidelines has shown that many of them take the view that general or broad consent is acceptable for unspecified future research use, if two conditions are met: a research ethics committee approves future projects and participants have the right to withdraw their samples at any time. This viewpoint is shared by Hansson, ${ }^{20}$ and is backed up by many empirical studies. Indeed, a meta-review of Wendler et $a^{21}$ of empirical studies regarding this topic has shown that a majority of donors do not object to broad consent, although other studies have pointed out that individuals want ongoing choices and control over access to their samples and information. ${ }^{22}$

Furthermore, in practice, broad consent seems to be the route taken by most biobanks to-date as well. An analysis of 52 European Network for Genetic and Genomic Epidemiology (ENGAGE) consent forms and information documents has shown that 27 of the studies involved used broad consent and 25 used specific consent, and that information sheets of 35 studies mentioned that the samples would be used for DNA extraction or genetic analysis. The information sheets of the remaining 17 did not mention genetic research per se but only biological research. ${ }^{23}$ The seminal UK biobank states in its consent form:

'I give permission for long-term storage and use of my blood and urine samples for health-related research purposes (even after my incapacity or death), and relinquish all rights to these samples which I am donating to UK Biobank. (http://www.ukbiobank.ac.uk/docs/2006ConsentformA.pdf)

Hence, the only limitation as to the content of the research being carried out is that it has to be 'health-related' research. The Estonian Gene Bank (http://www.geenivaramu.ee/index.php?id=100) has similar provisions, but it is even broader in specifying the type of research, in that it refers to 'The use thereof for genetic research, public health research and statistical and other purposes in accordance with the law.' Hence, they ask consent to virtually any type of research that is legally allowed.

\section{BROAD VERSUS SPECIFIC CONSENT IN PEDIATRIC BIOBANKS}

We believe that the issue of broad versus specific consent is even more complicated when participants are minors, as their parents provide 
consent for them. In the next paragraphs, we shall first describe the scarce literature that exists on this topic. Next, we shall discuss in more depth why we think this issue is further complicated and needs thorough reflection. We admit that the definition of 'broad consent' is in itself problematic, as it can refer to a whole range of items, from complete 'blanket' consent, to more restricted, but still fairly general consent. We shall use the term 'broad consent' as it is used in the literature, to refer to consent to unspecified future research, but under the supervision of a research ethics committee, whereas participants have the right to withdraw at any time.

\section{Broad versus specific consent in pediatric biobanks: empirical studies}

Not much study has been carried out with regard to the question of broad consent in pediatric biobanks. An overview of consent procedures in six cohort studies has shown that 'broad' consent is typically requested. One could argue, however, that that this is not really blanket consent, as the specific context of these studies allow for frequent contact between researchers, children and parents, thereby, providing many opportunities to reconsent. ${ }^{24}$ An interview-based study with professionals associated with pediatric biobanks has shown that they would prefer 'broad consent', but also think that if the research takes a too big step away from the original protocols, ethics committees should decide whether re-consent is necessary. ${ }^{7}$ These studies suggest a discrepancy between what is formally consented (which is fairly broad and includes any potential future research) and the actual practices researchers feel comfortable with. There seems to be a moral awareness among researchers that leads them to believe that re-consent is necessary for research that is very different from what is possible at the time of inception of the biobank. Hence, their interpretation of what is broad consent is more restricted than what the formal definition would suggest. Moreover, a survey among Belgian professionals has shown that for research on stored tissue samples from children, although there is still support for broad consent $(47.6 \%)$, more professionals would support specific consent $(79.4 \%) .{ }^{25}$ And a survey of Helgesson et $a^{26}$ of parents with and without earlier research experience showed that parents thought research studying the possible prevention of disease and research exploring the impact and importance of environmental factors were the most important followed by research into the role of genetic factors behind disease development. The least important research was deemed to be on medical substances and special groups of children. These findings suggest that parents (and possibly the general public) hold a certain value scheme about science, and that not all research is equally important to them. That being said, a survey by Neidich et al ${ }^{27}$ shows that women who were willing to enroll their children in a pediatric biobank put very little restrictions on the type of research that could be performed on these samples, with the exception of cloning.

\section{TWO PRESUPPOSITIONS}

We accept that, for biobanks containing only adult material, it may be perfectly acceptable that at time of donation some form of general consent is requested. We agree that this should not be completely blanket consent in that certain conditions should be met. Sensible conditions are the requirement that there is ethics committee oversight of the research proposals and donors have the right to withdraw their samples at any time. We also accept that parents are entitled to make certain decisions for their children, and that this is a fact of life. This fact seems not to be questioned by children either. ${ }^{28,11}$ Indeed, empirical studies on the enrollment of children in genetic biobank research have shown that overall parents are happy to enroll their children in biobank research, provided it is not burdensome or risky, and that it can aid other children. ${ }^{11,27}$ We agree that the decision to donate biological samples from children to genetic research is not too radical, provided that proper governance structures and data protection are put in place. ${ }^{29}$ In this respect, we disagree with authors who either argue that parents do not have the right to consent to the inclusion of their children's samples in biobanks, ${ }^{30}$ or that sharing of samples between research institutes should await the children's full consent. ${ }^{31}$

\section{Broad parental consent and its limitations}

We question the fact that the right to make decisions on behalf of children should include the right to give broad consent to any future unspecified genetic research on these samples. This belief is based on the idea that children are allowed to develop and express their own values, as they grow older, and that we should respect these values, and on the fact that medical research is not value-free. We shall elaborate on these ideas in the next paragraphs. In this respect, our concept of informed consent is not so much based on a contractual approach, in which the conditions and risks of participation are explained to participants who can then decide for themselves whether they would take these risks or not. ${ }^{32}$ Rather, it is based on a concept of consent as acknowledgement that individuals may hold certain values regarding research and on an acknowledgement of respect for these values. In this regard, our concept is linked with traditional concepts of consent, as a sign of respect of someone's autonomous right to hold certain values and his or her dignity as human person. This need not contradict with the assumption that biobanks and medical research can appeal to the solidarity of participants and, therefore, deploy consent strategies that are not completely analogous to informed consent. An autonomous person is always also a member of a community. ${ }^{33}$ In this regard, respect for values of individuals does not necessarily mean that each and every decision must be left to the individual but that circumstances can influence the decision of the individual. However, we do believe that children are a special case for that matter.

The fact that parents should not be allowed to give full broad consent to any possible research on their children's samples is linked to the special status of children. They are gradually becoming more autonomous in their thinking and are acquiring their own values as they grow older. Moreover, next to being a transitory phase toward adult autonomy, childhood is now more and more seen as a phase that is valuable and deserve respect in itself. Children may have different opinions and beliefs from those they shall have as adults, but this in itself is seen as something that should be respected. ${ }^{34}$ These opinions have now also been laid down in the Convention on the Rights of the Child: ${ }^{35}$

(article 12) 1. States Parties shall assure to the child who is capable of forming his or her own views the right to express those views freely in all matters affecting the child, the views of the child being given due weight in accordance with the age and maturity of the child.

With genetic research on biobank samples this poses specific issues. Typically, biobanks form a resource for potential future research, which is unknown at the time of the storage of samples. Although this may be perfectly acceptable for adults, who make the decision for themselves, for children some types of research may be too definite. As has been argued by Feinberg, children have a right to an open future. ${ }^{36}$ Choices made for children should not be too definite; in that, they should not prevent the children from making different choices themselves as soon as they are capable of doing so. An exception is 
made if such choices are deemed in the best interest of the child, in which parents are considered to be allowed to make definite choices, even contrary to the wishes of the child. Examples of such choices are life-saving operations or vaccinations. However, when parents give broad consent to any possibly future genetic research on the samples of their children, the best interest argument is not applicable. Moreover, such choice prevents children from making their own choices and revising these choices as they learn to become more autonomous. In case of biobanks, risks quoted are often related to privacy breaches and third-party access, such as the use of information by insurers or employers. As we have argued elsewhere, we think that such risks should be tackled by good governance and policy structures. ${ }^{29}$ But genetic privacy in itself is a value, regardless of the risks associated with third-party access. Hence, the publication of full genomes, which might reveal increasingly more information about the individual concerned as science progresses, should be up to that individual alone, and should not be considered part of any broad consent by parents. In this respect, Lunshof ${ }^{18}$ has described the idea of 'open' consent. We think that such 'open' consent can never be asked from parents for their children.

A second factor, which is related to the growing autonomy of children, is the fact that science and research are not completely valuefree. Although parents may, in good conscience, consent to future research on the samples of their children out of a feeling of altruism, and in line with the solidarity argument, 'for the benefit of science', their children may have a different opinion on what constitutes a valid research aim. As we have pointed out above, existing consent forms are vague as to the meaning of what is included in broad consent, and contain a general reference to either genetic or medical research. But does research investigating the relationship between genes and IQ or certain behavior fit this description? If the primary aim of a research proposal is the development of a prenatal test possibly leading to pregnancy termination, does it fall under the denominator 'healthrelated research'? As opinions vary on that, and are personal, it is indeed impossible to draw sharp dividing lines between what kind of research is comprised in a 'broad consent' and what is not, if the latter is not further specified or only described in general terms. We believe that genomic research, which has the potential to develop treatment or diagnosis for serious diseases, is legitimate, and not something many people would question. Hence, researchers and biobankers can appeal to solidarity of participants, including parents and children if such research is undertaken. ${ }^{16}$ But does research focusing on IQ, behavior or performance enhancement fit this description? We think that, although parents might be asked for consent to such research specifically, this should not be considered as part of the general consent for pediatric biobanks, and that some form of reconsent or notification is necessary in this case.

\section{Challenges}

There are some practical difficulties associated with our approach. We acknowledge that it is impossible to provide strict rules as to which type of research is included in the original parental consent and which research is possibly sensitive. We believe that the initial consent can be sufficiently broad to include research, which intends to prevent and treat relatively burdensome diseases. Ethics committees that supervise research proposals should evaluate whether the research falls under this category. Furthermore, biobank participants or their parents should have access to descriptions of goals and modalities of research, and have the opportunity to opt out of contributing. This can be carried out through a newsletter or a central website. As is already argued by Caulfield and Kaye ${ }^{15}$ for re-consent, the informatization of samples and medical data could also allow easy notification of participants through techniques such as E-mails or phone messages. Although this still may constitute an administrative overhead for researchers, who are then obliged to formulate proposals also in lay terms, it is a sign of respect for participants and their parents and ultimately it will enhance trust in, and education about the, biobank and science, in general.

A further difficulty is related to the difference between assent and consent. We do not suggest that parents cannot consent to research on tissue samples from their children if this research may be sensitive for some, only that they or their children should be given the opportunity to object to inclusion of their samples in such potentially sensitive research. We argue that there is a need for respect for the values of parents and specifically for children. Given the importance that should be given to the values and opinions of the children, they should be asked for their opinion and, if they are old enough, asked to assent as well. Practically, this respect may be translated in different forms depending on the type of collection. Most research on stored tissue samples from children requires extensive follow-up and hence frequent contact with parents and children. This will make it easier for researchers or associated clinicians to discuss the various types of research and assess the maturity of children. In case of research on stored tissue samples and data that does not require additional contacts after recruitment, parents and children should still be notified of new research using new techniques described above. Moreover, if there is limited contact between researcher and families, for example, because there was a one-time donation of a sample and no further information is gathered from the donors, a fixed-age threshold can be used at which young persons are contacted for full consent.

At which point, then, does the opinion of the young person become the only one that should be taken into account? There is no fixed answer to that, but we do believe that for the question of re-contacting and re-consenting to specific research protocols, the opinion of the child matters most. As there is not much risk involved, and as this is not a question of acting in the (medical) best interest of a child, such consent may be an excellent opportunity for children to reflect on their own values and exercise their growing autonomy. Hence, children who are below the legal age of consent may be asked for full consent in this case as well.

We have assumed that samples and information in biobanks are not completely de-identified and that re-contacting donors is possible. We admit that when samples are completely anonymized, it is impossible for biobank participants to be re-contacted or to withdraw samples. The issues related to complete anonymization have been discussed in some depth in the literature on biobanks. We believe in most cases, a coded system rather than complete anonymization is now used, as this provides sufficient privacy protection and takes away some of the drawbacks of complete anonymization. This may be especially true for pediatric research, as in most cases this requires some follow-up of participants.

\section{CONCLUSION}

One of the ethics issues associated with pediatric biobanks and genetic research on stored tissue samples from children is the question about the scope of parental consent. This scope has two dimensions. First, there is a temporal one. It is generally acknowledged that children, as they grow older and approach a certain level of maturity, should be allowed to have a say on what happens with their samples and possibly withdraw them from a collection. Hence, the temporal scope of parental consent is limited. Next, there is also the aspect of content. Should parents be allowed to give broad consent to any genetic research on their children's samples or only give specific consent? 
We have argued that, given the specificity of childhood, in which children are gradually acquiring their own values and developing their own autonomy, and the fact that medical research and science is value-laden, parents can give permission for research, which intends to understand and treat diseases. However, research that is more sensitive, such as behavioral research or IQ-related research, or research that would infringe the right to privacy, such as the publication of a child's full genome, would not be part of the original parental consent.

\section{CONFLICT OF INTEREST}

The authors declare no conflict of interest.

\section{ACKNOWLEDGEMENTS}

This work was supported by FWO Flanders; project number G029107. We thank Timothy Caulfield, Heidi Howard and the anonymous reviewer for their valuable suggestions.

1 Hens K, Nys H, Cassiman JJ, Dierickx K: Biological sample collections from minors for genetic research: a systematic review of guidelines and position papers. Eur J Hum Genet 2009; 17: 979-990.

2 Hens K, Nys H, Cassiman JJ, Dierickx K: Genetic research on stored tissue samples from minors: a systematic review of the ethical literature. Am J Med Genet A 2009; 149A: 2346-2358

3 Council for International Organizations of Medical Science (CIOMS): International Ethical Guidelines for Biomedical Research Involving Human Subjects. Geneva: CIOMS, 2002; http://www.cioms.ch/publications/layout_guide2002.pdf.

$4 \mathrm{Holm} \mathrm{S}$ : Informed consent and the bio-banking of material from children. Genomics Soc Policy 2005; 1: 16-26.

5 Pinxten W, Dierickx K, Nys H: The implementation of Directive 2001/20/EC into Belgian law and the specific provisions on pediatric research. Eur J Health Law 2008; 15: 1-9.

6 Helgesson G: Children, longitudinal studies, and informed consent. Med Health Care Philos 2005; 8: 307

7 Hens K, Dierickx K: The use of stored tissue samples from minors for genetic research. Interviews with professionals. New Genet Soc 2010; 29: 1-14

8 Ashcroft R, Goodenough T, Williamson E, Kent J: Children's consent to research participation: social context and personal experience in validate fixed cutoff rules. Am J Bioeth 2003; 3: 16-18.

9 Burke W, Diekema DS: Ethical issues arising from the participation of children in genetic research. J Pediatr 2006; 149(Suppl 1): 34-38.

10 Goldenberg AJ, Hull SC, Botkin JR, Wilfond BS: Pediatric biobanks: approaching informed consent for continuing research after children grow up. J Pediatr 2009; 155: 578-583.

11 Hens K, Nys H, Cassiman JJ, Dierickx K: The storage and use of biological tissue samples from minors for research: a Focus Group Study. Public Health Genomics 2011; e-pub ahead of print 10 April 2010, doi:10.1159/000294185.

12 Kaufman D, Geller G, LeRoy L, Murphy J, Scott J, Hudson K: Ethical implications of including children in a large biobank for genetic-epidemiologic research: a qualitative study of public opinion. Am J Med Genet 2008; 148C: 31-39.
13 Hoedemaekers R, Gordijn B, Pijnenburg M: Solidarity and justice as guiding principles in genomic research. Bioethics 2007; 21: 342-350.

14 Hansson MG: Need for a wider view of autonomy in epidemiological research. $B M J$ 2010; 340: c2335.

15 Caulfield T, Kaye J: Broad consent in biobanking: reflections on seemingly insurmountable dilemmas. Med Law Inter 2009; 10: 85-100.

16 Hoedemaekers R, Gordijn B, Pijnenburg M: Does an appeal to the common good justify individual sacrifices for genomic research? Theor Med Bioeth 2006; 27: 415-431.

17 Brekke OA, Sirnes T: Population biobanks: the ethical gravity of informed consent. BioSocieties 2006; 1: 385-398.

18 Lunshof JE, Chadwick R, Vorhaus DB, Church GM: From genetic privacy to open consent. Nat Rev Genet 2008; 9: 406-411.

19 Elger BS, Caplan AL: Consent and anonymization in research involving biobanks: differing terms and norms present serious barriers to an international framework. EMBO Rep 2006; 7: 661-666.

20 Hansson MG, Dillner J, Bartram CR, Carlson JA, Helgesson G: Should donors be allowed to give broad consent to future biobank research? Lancet Oncol 2006; 7: 266-269.

21 Wendler D: One-time general consent for research on biological samples. BMJ 2006; 332: 544-547.

22 Murphy J, Scott J, Kaufman D, Geller G, LeRoy L, Hudson K: Public perspectives on informed consent for biobanking. Am J Public Health 2009; 99: 2128-2134.

23 Tasse AM, Budin-Ljosne I, Knoppers BM, Harris JR: Retrospective access to data: the ENGAGE consent experience. Eur J Hum Genet 2010; 18: 741-745, ;.

24 Ries NM, Legrandeur J, Caulfield T: Handling ethical, legal and social issues in birth cohort studies involving genetic research: responses from studies in six countries. BMC Med Ethics 2010; 11: 4

25 Hens K, Snoeck J, Nys H, Cassiman JJ, Dierickx K: An exploratory survey of professionals on the use of stored tissue samples from minors for genetic research. Genet Mol Res 2010; 9: 973-980.

26 Helgesson G, Hansson MG, Ludvigsson J, Swartling U: What parents find important when participating in longitudinal studies: results from a questionnaire. Clinical Ethics 2010; 5: 28-34.

27 Neidich AB, Joseph JW, Ober C, Ross LF: Empirical data about women's attitudes towards a hypothetical pediatric biobank. Am J Med Genet 2008; 146: 297-304.

28 Goodenough T, Williamson E, Kent J, Ashcroft R: Ethical protection in research: including children in the debate; in Smyth M, Williamson E (eds): Researchers and Their 'Subjects'. Bristol: The Policy Press, 2004, pp 55-72.

29 Hens K, Wright J, Dierickx K: Biobanks: oversight offers protection. Science 2009; 326: 798-799.

30 Baumann TK: Proxy consent and a national DNA databank: an unethical and discriminatory combination. lowa Law Rev 2001; 86: 667-701.

31 Gurwitz D, Fortier I, Lunshof JE, Knoppers BM: Research ethics. Children and population biobanks. Science 2009; 325: 818-819.

32 Dickenson D: Risk and Luck in Medical Ethics. Oxford: Blackwell, 2003.

33 Rossello FT: The Limits of the Autonomy Principle. Philosophical Considerations; in Rendtorff JD, Kemp P (eds): Basic Ethical Principles in European Bioethics and Biolaw. Vol. II Partners' Researcg. Copenhagen and Barcelona, Centre for Ethics and Law and Institut Boja de Bioethica, 2010, pp 217-236.

34 Matthews GB: The Philosophy of Childhood. Cambridge and London, Harvard University Press, 1994.

35 United Nations Convention on the Rights of the Child. 1998; http://treaties.un.org/ Pages/ViewDetails.aspx?src=TREATY\&mtdsg_no=IV-11\&chapter=4\&lang=en.

36 Feinberg J: The Child's Right to an Open Future; in Aiken W, LaFollette H (eds): Whose Child? Children's Rights, Parental Authority and State Power. Totowa: Rowman and Littlefield, 1980, pp 124-153. 